\title{
Neurally adjusted ventilatory assist preserves cerebral blood flow velocity in patients recovering from acute brain injury
}

\author{
Gianmaria Cammarota ${ }^{1}(0) \cdot$ Federico Verdina ${ }^{2} \cdot$ Gianluigi Lauro $^{2} \cdot$ Ester Boniolo $^{2} \cdot$ Riccardo Tarquini $^{2}$. \\ Antonio Messina ${ }^{3} \cdot$ Nello De Vita $^{2} \cdot$ Ilaria Sguazzoti ${ }^{1} \cdot$ Raffaella Perucca $^{1} \cdot$ Francesco Della Corte $^{1,2}$. \\ Gian Luca Vignazia ${ }^{1} \cdot$ Francesca Grossi $^{1}$. Samuele Crudo ${ }^{2} \cdot$ Paolo Navalesi $^{4} \cdot$ Erminio Santangelo $^{2}$. \\ Rosanna Vaschetto ${ }^{1,2}$
}

Received: 23 March 2020 / Accepted: 5 May 2020 / Published online: 9 May 2020

(c) Springer Nature B.V. 2020

\begin{abstract}
Neurally adjusted ventilatory assist (NAVA) has never been applied in patients recovering from acute brain injury (ABI) because neural respiratory drive could be affected by intracranial disease with detrimental effects on cerebral blood flow (CBF) velocity. Our primary aim was to assess the impact of NAVA and pressure support ventilation (PSV) on CBF velocity. In fifteen adult patients recovering from ABI and undergoing invasive assisted ventilation, PSV and NAVA were applied over 30-min-lasting trials, in the following sequence: PSV ${ }_{1}$, NAVA, and PSV ${ }_{2}$. While PSV was set to deliver a tidal volume ranging between 6 and $8 \mathrm{ml} \mathrm{kg}^{-1}$ of predicted body weight, in NAVA the level of assistance was chosen to achieve the same inspiratory peak airway pressure as PSV. At the end of each trial, a sonographic evaluation of CBF mean velocity was bilaterally obtained on the middle cerebral artery and an arterial blood gas sample was taken for analysis. CBF mean velocity was $51.8[41.9,75.2] \mathrm{cm} \mathrm{s}^{-1}$ at baseline, $51.9[43.4,71.0] \mathrm{cm} \mathrm{s}^{-1}$ in PSV $_{1}, 53.6[40.7,67.7] \mathrm{cm} \mathrm{s}^{-1}$ in NAVA, and $49.5[42.1,70.8] \mathrm{cm} \mathrm{s}^{-1}$ in $\mathrm{PSV}_{2}(p=0.0514)$ on the left and $50.2[38.0,77.7] \mathrm{cm} \mathrm{s}^{-1}$ at baseline, $47.8[41.7,68.2] \mathrm{cm} \mathrm{s}^{-1}$ in $\mathrm{PSV}_{1}, 53.9[40.1,78.5] \mathrm{cm} \mathrm{s}^{-1}$ in NAVA, and $55.6[35.9,74.1] \mathrm{cm} \mathrm{s}^{-1}$ in $\operatorname{PSV}_{2}(p=0.8240)$ on the right side. No differences were detected for $\mathrm{pH}(p=0.0551)$, arterial carbon dioxide tension $(p=0.8142)$, and oxygenation $(p=0.0928)$ over the entire study duration. NAVA and PSV preserved CBF velocity in patients recovering from ABI.

Trial registration: The present trial was prospectively registered at www.clinicatrials.gov (NCT03721354) on October 18th, 2018.
\end{abstract}

Keywords Acute brain injury $\cdot$ Mechanical ventilation $\cdot$ Cerebral blood flow $\cdot$ Asynchronies

Electronic supplementary material The online version of this article (https://doi.org/10.1007/s10877-020-00523-w) contains supplementary material, which is available to authorized users.

Gianmaria Cammarota gmcamma@gmail.com

1 Department of Anesthesiology and Intensive Care, Azienda Ospedaliero-Universitaria "Maggiore Della Carità", Corso Mazzini18, 28100 Novara, Italy

2 Department of Translational Medicine, Università del Piemonte Orientale, Novara, Italy

3 Humanitas Clinical and Research Center - IRCCS, Rozzano, MI, Italy

4 Department of Medicine, University of Padua, Padua, Italy

\section{Introduction}

Invasive mechanical ventilation (IMV) is a life-saving intervention in patients admitted to intensive care unit (ICU) with diagnosis of severe acute brain injury [1]. However, IMV management is particularly challenging in this population since deep sedation and a tight control of the arterial carbon dioxide and oxygen tension as well as the intrathoracic pressure are recommended to avoid unsuitable cerebral blood flow changes, particularly at an early stage [2-4]. Thereafter, pressure support ventilation (PSV) is the most widespread ventilatory mode used to lead the patients towards the withdrawal of IMV [5]. However, during PSV, the mismatch between patient demand and mechanical assistance has been frequently reported in terms of asynchrony events, with negative consequences 
on patient-ventilator interaction (PVI) $[6,7]$. A poor PVI is associated with worse prognosis due to increased need for sedatives [8], prolongation of mechanical ventilation $[6,9]$, higher rate of tracheostomy [6], longer ICU and hospital stay [10], and increased mortality [11]. Accordingly, the loss of PVI could represent one reason of delayed withdrawal from IMV and/or extubation failure in neurocritical care patients too.

Neurally adjusted ventilatory assist (NAVA) is a ventilation mode in which the patient can assume the full control of ventilatory assistance in terms of timing and magnitude [12]. In general ICU patients, NAVA improves PVI during invasive and non-invasive ventilation respect to PSV [13-18]. This depends on several aspects: (1) contrarily to PSV where a pneumatic trigger is adopted, during NAVA the ventilator is triggered by patient's electrical activity of diaphragm (Eadi); (2) the ventilatory assistance is proportional to Eadi in NAVA, whereas in PSV the ventilatory support is fixed [12]. Thus, NAVA enhances the patient-ventilator synchrony, reduces the incidence of asynchronies, and improves the breath-bybreath variability of tidal volume $\left(\mathrm{V}_{\mathrm{T}}\right)$ compared to PSV [12], mimicking a more physiological behaviour [19]. Up to now, NAVA has never been applied to neurocritical care patients probably due to safety concerns on how the intracranial disease could affect Eadi signal, leading to unwanted modifications of arterial blood gases (ABGs) and cerebral blood flow velocity.

The present physiologic cross-over study was designed to investigate if NAVA could be safely employed in patients recovering from acute brain injury. Accordingly, the primary aim of our investigation was to ascertain and compare the effects of NAVA and PSV on mean cerebral blood flow velocity $\left(\mathrm{FV}_{\text {mean }}\right)$, bilaterally acquired through B-mode trans-cranial color-coded duplex (TCCD) sonography of middle cerebral artery (MCA), in patients recovering from acute brain injury. As additional endpoints the effects of the two ventilatory modes on ABGs as well as cerebral and systemic haemodynamics were investigated. Secondarily, the effects on PVI were assessed and compared between two ventilatory modes.

\section{Methods}

Our study was conducted according to the Helsinki Declaration principles, approved by the local Ethical Committee of Azienda Ospedaliero-Universitaria "Maggiore della Carità"- Novara, Italy (protocol No. CE 114/18) and registered at www.clinicatrials.gov (NCT03721354). Written informed consent was obtained for all subjects according to local regulations.

\subsection{Patients}

All adult patients, recovering from acute brain injury and undergoing IMV in PSV mode and continuous intracranial pressure (ICP) monitoring, were enrolled. Exclusion criteria were the following: ICP $>15 \mathrm{mmHg}$ with a $30^{\circ}$-headup position, documented vasospasm or mean cerebral blood flow velocity bilaterally assessed at middle cerebral artery $\geq 120 \mathrm{~cm} \mathrm{~s}^{-1}$ [20], hemodynamic instability despite adequate filling (i.e. need for continuous infusion of epinephrine or vasopressin, or dopamine $>5 \gamma \mathrm{kg}^{-1} \mathrm{~min}^{-1}$ or norepinehrine $>0.1 \gamma \mathrm{kg}^{-1} \mathrm{~min}^{-1}$ to maintain systolic arterial blood pressure $>90 \mathrm{mmHg}$ ) [14], core temperature $>38^{\circ} \mathrm{C}$, contraindication to gastro-esophageal catheter positioning [14], and pregnancy.

\subsection{Study protocol}

After the patients met the inclusion criteria, a dedicated feeding tube (Edi Catheter, Getinge, Sweden) was inserted and connected to the ventilator for the Eadi signal acquisition. The correct catheter position was assured as previously described [14].

The patients underwent three 30-min-lasting trials in the following sequence: $\mathrm{PSV}_{1}$, NAVA, and $\mathrm{PSV}_{2}$. In $\mathrm{PSV}_{1}$, inspiratory pressure support over positive end-expiratory pressure (PEEP) was titrated to obtain a $\mathrm{V}_{\mathrm{T}}$ of $6-8 \mathrm{ml}^{-1} \mathrm{~kg}^{-1}$ of predicted body weight. The flow trigger was set as more sensible as possible, avoiding auto-triggers, and the expiratory cycle-off threshold was $30 \%$ of the peak inspiratory flow. Then, the corresponding level of assistance in NAVA was chosen through a specific ventilator tool (NAVApreview, Getinge, Sweden) that, during PSV, matches the NAVA gain to get an equivalent peak of inspiratory pressure [14]. Afterwards, the ventilator was switched to PSV, and $\mathrm{PSV}_{1}$ setting parameters were restored $\left(\mathrm{PSV}_{2}\right)$. PEEP and inspired oxygen fraction were maintained constant at the pre-enrolment values over the whole study duration. The level of sedation was assessed through Richmond Agitation Sedation Scale at study entry, immediately after the definitive catheter positioning, and held stable at each study step. The last minute of each trial was recorded, stored on a personal computer, and furtherly analysed.

\subsection{Measurements and data analysis}

At the end of each trial, an arterial blood sample was taken to obtain the blood gas analysis. Simultaneously, across the temporal window, $\mathrm{FV}_{\text {mean }}$ and pulsatility index (PI) of MCA were blindly assessed through a 2-MHz-TCCD machine (Xario 200, Toshiba Medical System, Japan) on each side, being MCA 
flow a rough representation of the ipsilateral hemisphere blood flow [21, 22]. During each assessment, after the MAC identification, the probe position was adjusted, by assuring an insonation angle $<30^{\circ}$ [23], to scan the blood flow velocity at 3 different sampling distances, approximatively: $60 \mathrm{~mm}, 45 \mathrm{~mm}$, and $35 \mathrm{~mm}$ [22]. From the vessel segment showing the highest blood velocity, $\mathrm{FV}_{\text {mean }}$ and PI were computed as the time-mean value of the velocity spectrum outline from 10 consecutive cardiac cycles [24]. ICP, cranial perfusion pressure (CPP), mean arterial pressure, and heart rate were monitored throughout the whole study duration and their average values were collected during the last minute of each trial and finally analysed.

Airflow, airway pressure (Paw) and Eadi were recorded from the ventilator by a dedicated software (Nava Tracker, Getinge, Sweden) through a RS232 interface, at a 100-Hzsampling rate, stored on a personal computer, and analysed using a specific software (ICU-Lab, KleisTek, Bari, Italy). Paw and Eadi peak were measured. From flow trace mechanical respiratory rate, inspiratory and expiratory time, total breath duration, inspiratory duty cycle, and $\mathrm{V}_{\mathrm{T}}$, by digital integration, were obtained [14]. Neural respiratory rate, inspiratory and expiratory time, total breath duration, inspiratory duty cycle were attained from Eadi waveform [14]. Inspiratory and expiratory trigger delay as well as time of synchrony, also indexed on neural inspiratory time and expressed in percentage, were calculated [13, 17]. The asynchrony index was computed as total amount of macroasynchrony events (ineffective efforts, double triggers, autotriggers and reverse triggers) on the sum of triggered and non-triggered breaths ratio and expressed in percentage [25]. An asynchrony index $\geq 10 \%$ was deemed suggestive for high rate of macroasynchrony [6]. Finally, the coefficient of variation for $\mathrm{V}_{\mathrm{T}}$, mechanical respiratory rate, and Eadi and Paw peak were calculated (standard deviation to mean ratio multiplied by 100) as previously described [14].

The sample size of the present study was chosen in keeping with a previous investigation ascertaining the physiologic response to NAVA application in intubated acute respiratory failure patients [14]. Data are presented as median and [25th, 75th percentile]. According to the non-normal distribution of the data, Friedman's test with Dunn's multiple comparisons post-hoc test for repeated measure were employed. The number of patients with Asynchrony index $\geq 10 \%$ was compared among PSV , NAVA, and PSV $_{2}$ using Chi-square test. Data analysis was conducted through a dedicated statistical software (Prism 8, Graphpad, California).

\section{Results}

From November 2018 to August 2019, a total number of 22 patients, recovering from acute brain injury, were screened for eligibility, 15 of whom were enrolled and finally analysed
(Supplemental digital content 1). Patients general characteristics and clinical features at the time of enrolment are reported in Table 1.

As described in Table 2, the $\mathrm{FV}_{\text {mean }}$ and PI, assessed at middle cerebral artery on each side, remained stable over the whole study period, without difference among ventilatory modes. Moreover, ICP and CPP as well as systemic haemodynamics and ABGs did not change switching from $\mathrm{PSV}_{1}$ to NAVA and from NAVA to PSV ${ }_{2}$. Only lactate was reduced moving from $\mathrm{PSV}_{1}$ to NAVA $(\mathrm{p}=0.0433)$ without clinical relevance.

Breathing pattern and PVI are reported in Table 3. Expired $\mathrm{V}_{\mathrm{T}}$, mechanical and neural respiratory rate and timing were not affected by ventilatory mode running. No differences regarding PEEP and Paw peak were detected between $\mathrm{PSV}_{1}, \mathrm{NAVA}$, and $\mathrm{PSV}_{2}$. Peak of Eadi was reduced moving from NAVA to $\mathrm{PSV}_{2}(p=0.0318)$. Inspiratory trigger delay improved switching from $\mathrm{PSV}_{1}$ to NAVA $(p=0.0105)$, whereas expiratory trigger delay decreased during NAVA compared to that recorded during both $\operatorname{PSV}_{1}(p=0.0185)$ and $\operatorname{PSV}_{2}(p=0.0185)$, respectively. Time of synchrony ameliorated with NAVA application respect to $\mathrm{PSV}_{1}$ $(p=0.0185)$ and, when indexed to neural time, it was greater in NAVA compared to both $\mathrm{PSV}_{1}(p=0.0016)$ and $\mathrm{PSV}_{2}$ $(p=0.0381)$. Unlike NAVA, PSV induced a wide worsening of asynchrony index in both trials (vs $\mathrm{PSV}_{1} p=0.0318$; vs $\mathrm{PSV}_{2} p=0.0243$ ) and, as depicted in Fig. 1, the number of patients who experienced an asynchrony index $\geq 10 \%$ was $11 / 15$ (73.3\%) in $\mathrm{PSV}_{1}, 5 / 15$ (30\%) in NAVA, and 15/15 $(100 \%)$ in $\mathrm{PSV}_{2}(p=0.0004)$, respectively.

Figure 2 shows the incidence of macroasynchrony events recorded over the whole study duration. Ineffective efforts and autotriggers mainly occurred during $\mathrm{PSV}_{1}(62.07 \%$; $26.44 \%)$ and $\mathrm{PSV}_{2}(67.07 \% ; 30.49 \%)$. On the contrary, double triggers were poorly represented, being $11.49 \%$ and $2.44 \%$ of the total amount of asynchrony events in $\mathrm{PSV}_{1}$ and $\mathrm{PSV}_{2}$, respectively. In NAVA, ineffective efforts, autotriggers, and double triggers accounted for $39.13 \%, 43.48 \%$, and $17.39 \%$ of the total number of macroasynchronies detected, respectively. No reverse triggers were noted during all the trials.

The variability of $\mathrm{V}_{\mathrm{T}}$, mechanical respiratory rate, Paw and Eadi peak are reported in Table 4. Coefficient of variation of $\mathrm{V}_{\mathrm{T}}$ and peak of Paw were higher in NAVA than in $\mathrm{PSV}_{1}(p=0.0004 ; p=0.0030)$ and $\mathrm{PSV}_{2}(p=0.0185$; $p<0.0001)$, respectively.

\section{Discussion}

The main findings of our study can be summarized as follows: (1) in a very short time frame, NAVA and PSV were safely employed in our neurocritical care patients, as $\mathrm{FV}_{\text {mean }}$, 


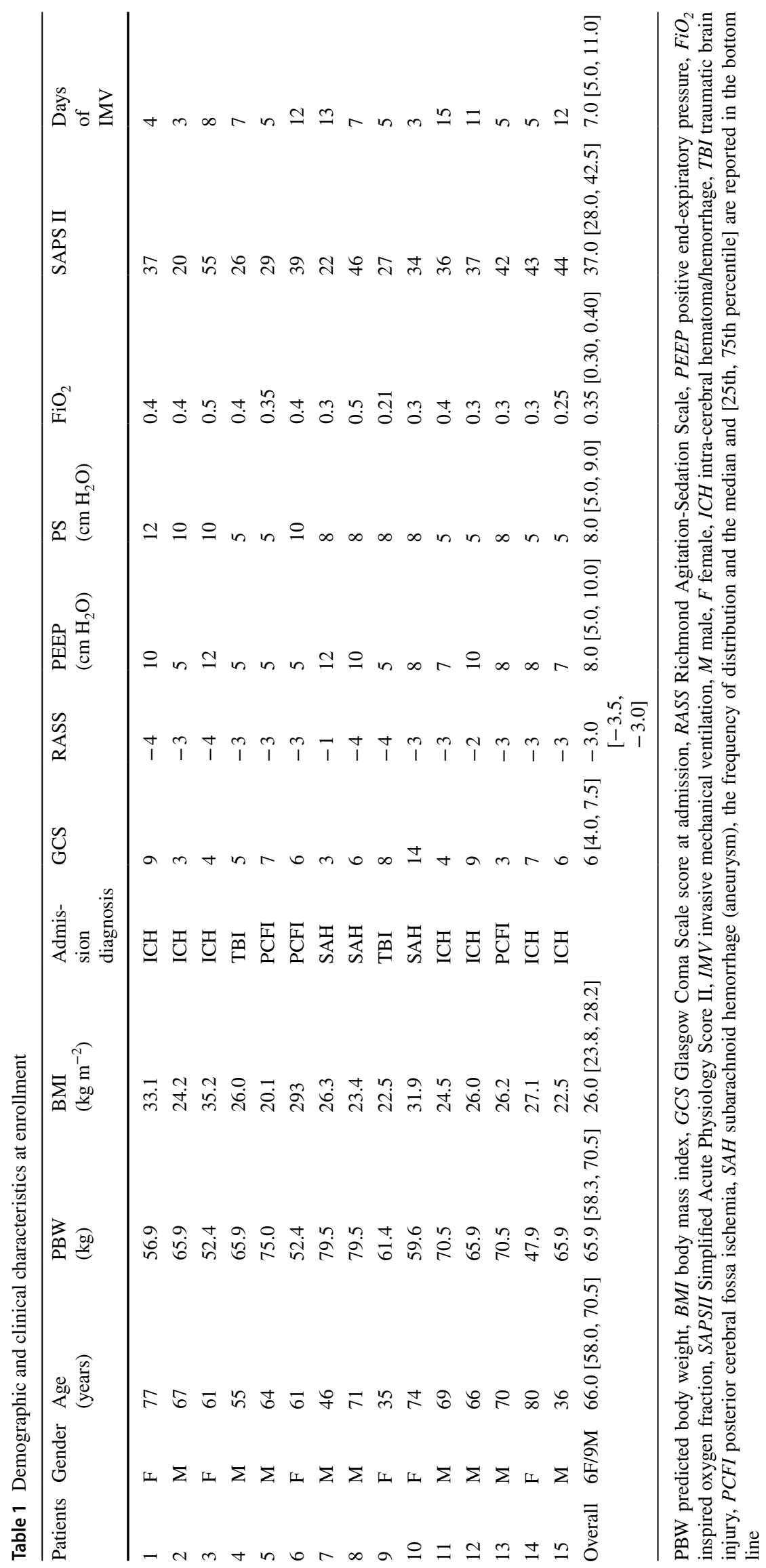


Table 2 Cerebral blood flow velocity, intracranial pressure, hemodynamics, and arterial blood gases

\begin{tabular}{|c|c|c|c|c|c|}
\hline \multirow[t]{2}{*}{ Variables } & \multicolumn{5}{|l|}{ Study steps } \\
\hline & Baseline & $\mathrm{PSV}_{1}$ & NAVA & $\mathrm{PSV}_{2}$ & $p$-value \\
\hline \multicolumn{6}{|c|}{ MCA Cerebral blood flow velocity } \\
\hline Left $\mathrm{FV}_{\text {mean }}\left(\mathrm{cm} \mathrm{s}^{-1}\right)$ & $51.8[41.9,75.2]$ & $51.9[43.4,71.0]$ & $53.6[40.7,67.7]$ & $49.5[42.1,70.8]$ & 0.0514 \\
\hline Right $\mathrm{FV}_{\text {mean }}\left(\mathrm{cm} \mathrm{s}^{-1}\right)$ & $50.2[38.0,77.7]$ & $47.8[41.7,68.2]$ & $53.9[40.1,78.5]$ & $55.6[35.9,74.1]$ & 0.8240 \\
\hline Left PI & $1.3[1.1,1.5]$ & $1.3[1.2,1.5]$ & $1.3[1.2,1.5]$ & $1.4[1.2,1.5]$ & 0.7491 \\
\hline Right PI & $1.3[1.3,1.4]$ & $1.4[1.1,1.5]$ & $1.3[1.1,1.5]$ & $1.3[1.1,1.5]$ & 0.8710 \\
\hline \multicolumn{6}{|c|}{ Intracranial pressure and hemodynamics } \\
\hline ICP (mm Hg) & $5.0[2.0,10.0]$ & $4.0[3.0,8.0]$ & $6.0[3.0,9.0]$ & $5.0[3.0,10.0]$ & 0.9189 \\
\hline $\mathrm{CPP}(\mathrm{mm} \mathrm{Hg})$ & $88.0[66.0,90.0]$ & $80.0[72.7,90.0]$ & $82.0[76.0,87.0]$ & $82.0[72.0,93.0]$ & 0.6700 \\
\hline \multicolumn{6}{|l|}{ Systemic hemodynamics } \\
\hline MAP (mm Hg) & $93.0[79.0,98.0]$ & $87.0[77.0,93.0]$ & $90.0[78.7,95]$ & $89.0[79.0,97.0]$ & 0.2959 \\
\hline HR (beats $\min ^{-1}$ ) & $80.0[64.0,88.0]$ & $76.0[65.0,92.0]$ & $74.0[65.0,90.0]$ & $72.0[63.0,97.0]$ & 0.1940 \\
\hline \multicolumn{6}{|l|}{ Arterial blood gases } \\
\hline $\mathrm{pH}$ & $7.4[7.4,7.5]$ & $7.4[7.4,7.5]$ & $7.4[7.4,7.5]$ & $7.4[7.4,7.5]$ & 0.0551 \\
\hline $\mathrm{PaCO}_{2}(\mathrm{~mm} \mathrm{Hg})$ & $41.9[39.4,45.5]$ & $42.2[38.6,45.2]$ & $43.4[39.3,45.5]$ & $40.9[39.5,45.7]$ & 0.8142 \\
\hline $\mathrm{PaO}_{2} / \mathrm{FiO}_{2}(\mathrm{~mm} \mathrm{Hg})$ & $222.0[199.0,260.0]$ & $235.0[198.0,284.0]$ & $264.0[226.0,305.0]$ & $278.0[197.0,304.0]$ & 0.0928 \\
\hline Lactate $\left(\mathrm{mmol}^{-1}\right)$ & $0.7[0.5,1.0]$ & $0.7[0.5,1.1]$ & $0.6[0.4,0.9]^{*}$ & $0.6[0.4,1.0]$ & 0.0044 \\
\hline
\end{tabular}

Data are presented as median and [25th, 75th percentile]. $p$-values derive from non-parametric Friedman's test for repeated measures, whereas symbols refer to $p$-values from multiple comparison post-hoc Dunn's test

$P S V_{1}$ pressure support ventilation mode trial $1, N A V A$ neurally adjusted ventilatory assist ventilation mode, $P S V_{2}$ pressure support ventilation mode trial 2, MCA middle cerebral artery, $F V_{\text {mean }}$ mean cerebral blood flow velocity assessed at MCA through transcranial color duplex sonography technique, $P I$ pulsatility index assessed at MCA through transcranial color doppler technique, $I C P$ intracranial pressure, $C P P$ cerebral perfusion pressure, $\mathrm{MAP}$ mean arterial pressure, $\mathrm{HR}$ heart rate, $\mathrm{PaCO}_{2}$ arterial carbon dioxide tension, $\mathrm{PaO}_{2} / \mathrm{FiO}_{2}$ arterial oxygen tension on inspired oxygen fraction ratio

$* p<0.05$ vs. Baseline

PI, ABGs, cerebral and systemic haemodynamics were stable over all study duration; (2) in our series, NAVA, contrarily to PSV, improved PVI by ameliorating patient-ventilator synchrony, reducing the macroasynchronies incidence, and providing a better breath-by-breath $\mathrm{V}_{\mathrm{T}}$ and Paw peak variability.

Cerebral blood flow is the most important determinant of oxygen delivery to brain [26]. In acutely brain-injured patients, the cerebral blood flow and oxygen delivery optimization depends on ICP [27, 28], CPP [27, 28], carbondioxide tension [29, 30], and systemic oxygenation [31]. Accordingly, mechanical ventilation should be set to improve systemic oxygenation [31], to maintain an arterial carbon dioxide tension within a $32-45 \mathrm{mmHg}$ range [32], and to prevent excessive rise of intrathoracic pressure that could induce the worsening of CPP [33], especially in the early stages of acute brain injury.

Following the early phases of acute brain injury, PSV is commonly employed as a safe ventilatory strategy during the weaning process from IMV $[5,34]$. Here we show that both PSV and NAVA were securely applied in our setting, since $\mathrm{FV}_{\text {mean }}$, assessed at MCA on each side through TCCD sonography, was equally preserved by both ventilatory modes. This finding could be ascribed to three mechanisms;
(1) the absence of pathological modifications of ICP during the entire study period, as also suggested by the fact that PI did not change over the trials [35]; (2) the lack of clinically relevant variations of cerebral and systemic haemodynamics, in agreement with the fact that CPP and mean arterial pressure did not change switching from PSV to NAVA; (3) the preservation of a physiological arterial carbon dioxide tension and ABGs overall, despite the mode of ventilation running. This aspect was particularly relevant, because it confirmed that the negative feedback loop of chemical control of respiration was preserved in our population. Indeed, we could speculate that the alveolar ventilation was similar among ventilation modes, as suggested by the absence of modifications of $\mathrm{V}_{\mathrm{T}}$, mechanical respiratory rate, and arterial carbon dioxide tension among trials. In NAVA, this was the result of a higher respiratory centre output, as confirmed by a greater Eadi peak compared to that detected in $\mathrm{PSV}_{1}$ and $\mathrm{PSV}_{2}$, respectively. Thus, being the ventilatory support applied in proportion to Eadi [12], in NAVA, the mechanical ventilation was fully controlled by patient's own respiratory centres.

Despite the level of assistance, NAVA assured a lowtidal protective ventilation, in general acute respiratory failure patients [14]. In line with previous findings, in our 
Table 3 Breathing pattern, and patient-ventilator interaction

\begin{tabular}{|c|c|c|c|c|}
\hline \multirow[t]{2}{*}{ Variables } & \multicolumn{4}{|l|}{ Study steps } \\
\hline & $\mathrm{PSV}_{1}$ & NAVA & $\mathrm{PSV}_{2}$ & $p$-value \\
\hline \multicolumn{5}{|l|}{ Breathing pattern } \\
\hline Expired $\mathrm{V}_{\mathrm{T}}\left(\mathrm{ml} \mathrm{kg}^{-1}\right.$ of PBW $)$ & $7.3[6.4,7.9]$ & $6.9[6.5,8.2]$ & $6.8[6.2,7.8]$ & 0.0569 \\
\hline $\mathrm{RR}_{\text {mec }}$ (mechanical breathes $\min ^{-1}$ ) & $18.4[15.9,21.9]$ & $18.1[15.0,26.5]$ & $17.3[15.5,24.8]$ & 0.4841 \\
\hline $\mathrm{RR}_{\text {neu }}\left(\right.$ neural breathes $\left.\min ^{-1}\right)$ & $19.0[15.0,25.0]$ & $17.0[14.0,25.0]$ & $19.0[16.0,29.0]$ & 0.2588 \\
\hline $\mathrm{TI}_{\mathrm{mec}}(\mathrm{s})$ & $1.0[0.9,1.2]$ & $0.9[0.7,1.2]$ & $0.9[0.9,1.2]$ & 0.0743 \\
\hline $\mathrm{TI}_{\text {neu }}(\mathrm{s})$ & $1.1[0.9,1.3]$ & $1.1[0.9,1.3]$ & $1.1[0.8,1.2]$ & 0.4204 \\
\hline $\mathrm{TE}_{\mathrm{mec}}(\mathrm{s})$ & $2.4[1.8,2.7]$ & $2.0[1.6,2.8]$ & $2.5[1.5,3.1]$ & 0.6271 \\
\hline $\mathrm{TE}_{\mathrm{neu}}(\mathrm{s})$ & $1.0[0.9,1.1]$ & $1.1[1.0,1.2]$ & $1.1[1.0,1.2]$ & 0.0381 \\
\hline TI/TTOT $_{\mathrm{mec}}$ & $0.3[0.3,0.5]$ & $0.3[0.3,0.4]$ & $0.3[0.3,0.4]$ & 0.6271 \\
\hline TI/TTOT $_{\text {neu }}$ & $0.5[0.5,0.5]$ & $0.5[0.4,0.5]$ & $0.5[0.4,0.5]$ & 0.2818 \\
\hline \multicolumn{5}{|l|}{ Patient-ventilator interaction } \\
\hline $\operatorname{PEEP}\left(\mathrm{cm} \mathrm{H}_{2} \mathrm{O}\right)$ & $7.9[4.7,9.9]$ & $7.6[4.9,10.0]$ & $7.6[4.7,9.8]$ & 0.4080 \\
\hline $\mathrm{Paw}_{\text {peak }}\left(\mathrm{cm} \mathrm{H}_{2} \mathrm{O}\right)$ & $14.4[11.2,15.6]$ & $13.3[10.3,16.2]$ & $13.0[11.0,15.5]$ & 0.6271 \\
\hline $\operatorname{Eadi}_{\text {peak }}(\mu \mathrm{V})$ & $2.1[1.5,5.5]$ & $3.4[2.4,7.3]$ & $2.5[1.9,4.2]^{\dagger}$ & 0.0171 \\
\hline Inspiratory Delay $_{\text {trigger }}(\mathrm{s})$ & $0.4[0.3,0.6]$ & $0.2[0.2,0.3]^{*}$ & $0.4[0.4,0.5]$ & 0.0115 \\
\hline Expiratory Delay $_{\text {trigger }}(\mathrm{s})$ & $0.3[0.2,0.5]$ & $0.2[0.2,0.3]^{*}$ & $0.3[0.3,0.5]^{\dagger}$ & 0.0067 \\
\hline $\mathrm{T}_{\text {synch }}(\mathrm{s})$ & $0.7[0.5,0.8]$ & $0.8[0.6,1.1]^{*}$ & $0.6[0.4,0.8]$ & 0.0150 \\
\hline $\mathrm{T}_{\text {synch }} / \mathrm{TI}_{\text {neu }}(\%)$ & $57.6[45.6,70.1]$ & $79.8[64.5,84.1]^{*}$ & $58.0[46.7,68.8]^{\dagger}$ & 0.0016 \\
\hline Asynchrony Index (\%) & $20[7.1,31.4]$ & $3.4[0.0,11.1]^{*}$ & $17.7[14.3,25]^{\dagger}$ & 0.0079 \\
\hline
\end{tabular}

Data are presented as median and [25th, 75th percentile]. $p$-values derive from non-parametric Friedman's test for repeated measures, whereas symbols refer to $p$-values from multiple comparison post-hoc Dunn's test

$P S V_{l}$ pressure support ventilation mode trial 1, NAVA neurally adjusted ventilatory assist ventilation mode, $P S V_{2}$ pressure support ventilation mode trial 2, $V_{T}$ expired tidal volume on predicted body weight ratio, $R R_{\text {mec }}$ mechanical respiratory rate, $R R_{\text {neul }}$ neural respiratory rate, $T I_{\text {mес }}$ mechanical inspiratory time, $T I_{\text {neu }}$ neural inspiratory time, $T E_{\text {mec }}$ mechanical expiratory time, $T E_{\text {neu }}$ neural expiratory time, TI/TTOT mec mechanical inspiratory duty cycle, $T I / T T O T_{\text {neu }}$ neural inspiratory duty cycle, $P E E P$ positive end-expiratory pressure, $P a w_{\text {peak }}$ peak of airway inspiratory pressure, Eadi $i_{\text {peak }}$ peak of electrical activity of diaphragm, Inspiratory Delay trigger inspiratory trigger delay, Expiratory Delay $y_{\text {trigger }}$ expiratory trigger delay, $T_{\text {synch }}$ Time of synchrony between neural effort and ventilatory support, $T_{\text {svnch }} T I_{\text {пеи }}(\%)$ ratio expressed in percentage, between time during which respiratory effort and ventilator assistance are synchronous on $\mathrm{TI}_{\text {neu }}$

$* p<0.05$ vs $\mathrm{PSV}_{1} ;{ }^{\dagger} p<0.05$ vs. NAVA

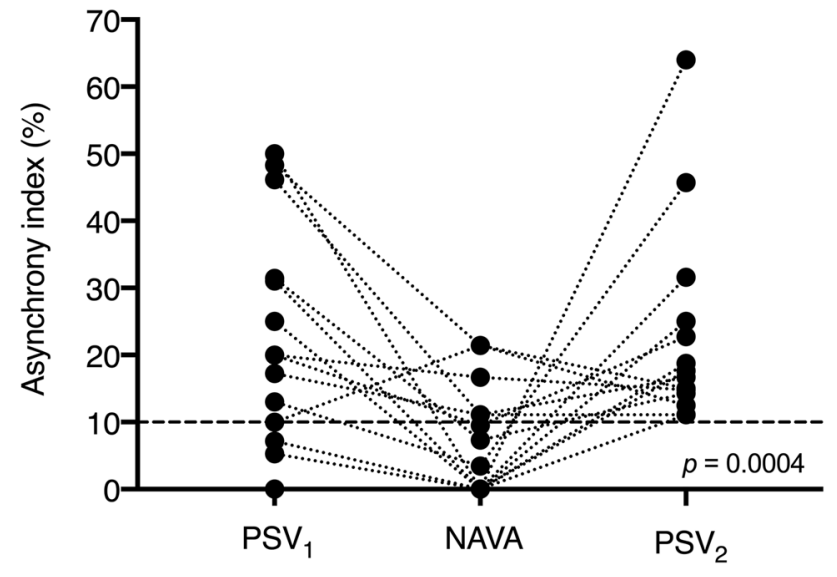

Fig. 1 Asynchrony index. The asynchrony index of each patient during all study trials are depicted. $P S V_{l}$ pressure support ventilation trial $1, N A V A$ neurally adjusted ventilatory assist ventilation, $P S V_{2}$ pressure support ventilation trial $2 ; p$-value is referred to Chi-square test among PSV ${ }_{1}$, NAVA, and $\mathrm{PSV}_{2}$ for asynchrony index $\geq 10 \%$ series, a protective ventilation strategy was adopted and maintained both through PSV and NAVA, being $\mathrm{V}_{\mathrm{T}}$ persistently $<8 \mathrm{ml}^{-1} \mathrm{~kg}^{-1}$ of predicted body weight during whole study duration. This could be particularly interesting in patients recovering from acute brain injury with a coexisting acute lung injury. In fact, it has been demonstrated that the neurocritical care patients undergoing high-tidal mechanical ventilation are more prone to ventilator-induced-lung-injury occurrence [36]. In keeping with our results, NAVA could represent a good solution to assure a low-tidal-protective ventilation and prevent ventilator-induced-lung injury after the early phases of acute brain injury.

NAVA, compared to PSV, improves PVI in adult patients, admitted in ICU and undergoing invasive and non-invasive mechanical ventilation, through several mechanisms [13-15, 17, 18, 37, 38]. First of all, NAVA ameliorates the patient-ventilator synchrony by reducing the inspiratory and expiratory trigger delay $[13,15]$ and increasing the time of 
A

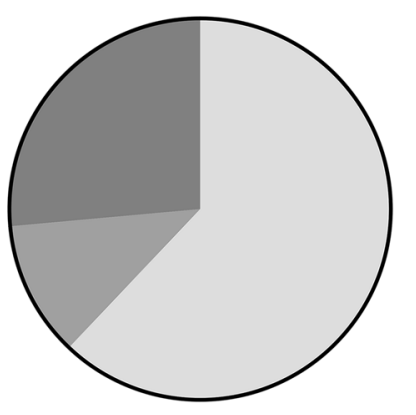

B
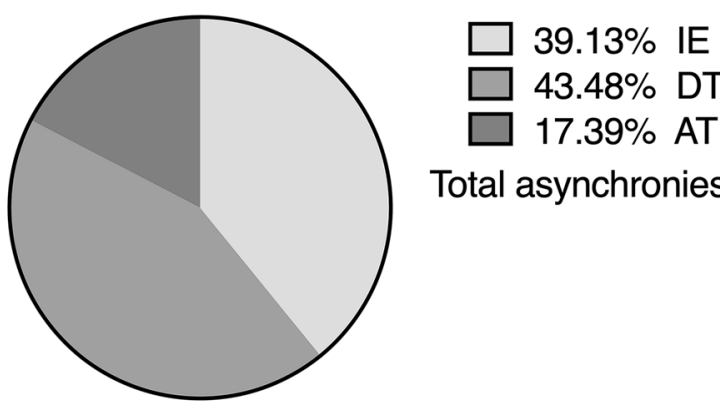

$\square 43.48 \%$ DT $\square 17.39 \%$ AT

Total asynchronies $=23$

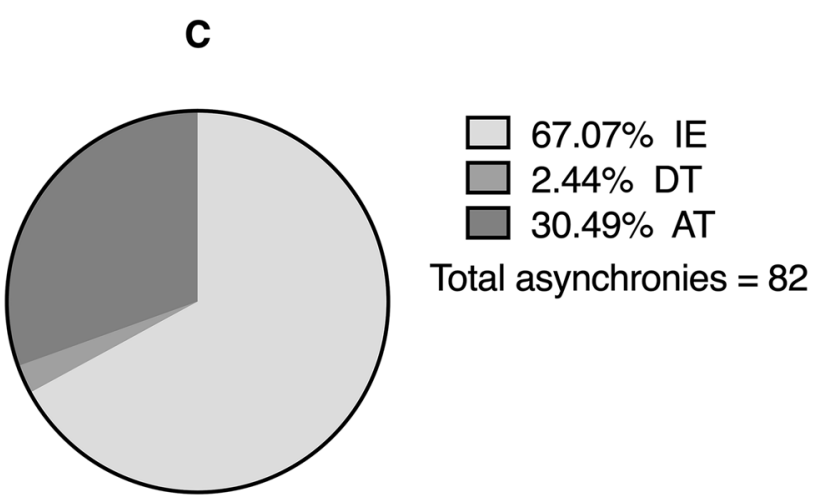

Fig. 2 Macroasynchrony events. The total number of macroasynchrony events and the percentages of the specific types of asynchronies are depicted. Light grey, $I E$ ineffective efforts; middle grey, $D T$ double triggers; dark grey, $A T$ auto-triggers. a Pressure support ventilation trial 1; b neurally adjusted ventilatory assist; $\mathbf{c}$ pressure support ventilation trial 2

synchrony between patient's own neural inspiratory effort and ventilatory assistance, as previously reported also during non-invasive ventilation [17, 18]. In good agreement with previous investigations [13-15, 17, 18, 37, 38], also in our study patient-ventilator matching was better during NAVA application compared to that observed in PSV. Indeed, the inspiratory and expiratory trigger delay in NAVA were shorter than those recorded in PSV. In addition, in our patients, the time of synchrony, on average, accounted for $74.3 \%$ of neural inspiratory time in NAVA and $56.8 \%$ and $55.3 \%$ in $\mathrm{PSV}_{1}$ and $\mathrm{PSV}_{2}$, respectively.

Generally, during NAVA, the asynchrony index and the incidence of macroasynchrony events are reduced respect to PSV in invasively and non-invasively ventilated patients [14-18]. In good agreement with previous investigations [14-18], also in our setting NAVA improved PVI by diminishing asynchrony index and macroasynchronies occurrence compared to $\mathrm{PSV}_{1}$ and $\mathrm{PSV}_{2}$, respectively. Indeed, only $30 \%$ of patients experienced an asynchrony index $\geq 10 \%$ in NAVA against $73.3 \%$ and $100 \%$ in $\mathrm{PSV}_{1}$ and $\mathrm{PSV}_{2}$, respectively. Thus, the total amount of macroasynchronies was lower in NAVA compared to both PSV trials. Taking into account the different types of asynchronies detected, in $\mathrm{PSV}_{1}$ and $\mathrm{PSV}_{2}$ the ineffective efforts were the most detected asynchrony events (among $62 \%$ and $67 \%$ ), followed by autotriggers (among 26\% and 30\%) and double triggers (among 11\% and $2 \%$ ). Contrariwise, in NAVA, the double triggers (43\%) occurred more frequently compared to the ineffective efforts (39\%) and autotriggers (17\%). No reverse triggers were observed during all the trials. These findings are in line with previous results achieved in intubated patients with acute respiratory failure $[15,16]$, also undergoing weaning trial [39]. What is novel in our results is that, regardless of ventilatory mode, the asynchrony index and the macroasynchrony events incidence were higher in our patients compared to those reported in previous investigations [14-16, 39]. This could depend on two aspects: (1) neurocritical patients are more prone to asynchronies development probably because of different respiratory drive characteristics [40] compared to those described in acute respiratory failure [14-16]; (2) in handling with acute brain injury, deep sedation levels are more frequently achieved and longer maintained [4] compared to the sedation plans adopted in intubated general ICU patients, with the well-described effects on neural respiratory drive and breathing pattern [41, 42], safety, and outcomes $[43,44]$.

NAVA enhances PVI preserving the breath-by-breath variability of $\mathrm{V}_{\mathrm{T}}$ mimicking the physiological behaviour of healthy individuals $[14,19]$. As matter of fact, while the ventilatory assistance delivered in NAVA is proportional to Eadi [12], during PSV, the patients receive a fixed ventilatory support that, in some cases, leads to lose the control of their own breathing pattern [45]. In keeping with previous works, also in our study, $\mathrm{V}_{\mathrm{T}}$ and Paw peak variability were better preserved in NAVA compared to those reported in $\mathrm{PSV}_{1}$ and $\mathrm{PSV}_{2}$. On the contrary, the variability of mechanical respiratory rate and Eadi peak were similar among ventilatory modes. Thus, in our neurocritical care patients, a more variable breathing pattern was assured in NAVA, compared to $\mathrm{PSV}_{1}$ and $\mathrm{PSV}_{2}$. Noteworthy, two patients developed in NAVA a Cheyne-Stokes respiration that was barely 
Table 4 Variability of breathing pattern

\begin{tabular}{lcrrr}
\hline Variables & \multicolumn{3}{l}{ Study steps } & \\
\cline { 2 - 5 } & \multicolumn{1}{l}{ PSV $_{1}$} & NAVA & PSV $_{2}$ & $p$-value \\
\hline Breathing pattern & & & & \\
$\mathrm{V}_{\mathrm{T}}-\mathrm{CV}(\%)$ & $5.1[2.8,12.5]$ & $19.8[9.5,26.7]^{*}$ & $9.1[4.9,15.5]^{\dagger}$ & 0.0004 \\
$\mathrm{RR}_{\text {mec }}-\mathrm{CV}(\%)$ & $7.0[4.7,12.0]$ & $8.2[5.4,28.6]$ & $10.3[6.0,17.7]$ & 0.6271 \\
Paw $_{\text {peak }}-\mathrm{CV}(\%)$ & $2.8[1.1,3.3]$ & $14.8[8.3,17.5]^{*}$ & $2.2[1.2,4.7]^{\dagger}$ & $<0.0001$ \\
Eadi $_{\text {peak }}-\mathrm{CV}(\%)$ & $29.4[16.8,40.1]$ & $26.5[19.3,34.1]$ & $28.0[19.4,34.2]$ & 0.6271 \\
\hline
\end{tabular}

Data are presented as median and [25th, 75th percentile]. $p$-values derive from non-parametric Friedman's test for repeated measures, whereas symbols refer to $p$-values from multiple comparison post-hoc Dunn's test

$P S V_{1}$ pressure support ventilation mode trial $1, N A V A$ neurally adjusted ventilatory assist ventilation mode, $\mathrm{PSV}_{2}$ pressure support ventilation mode trial $2, V_{T}-C V$ coefficient of variation of expired tidal volume, $R R_{\text {mec }}-C V$ coefficient of variation of mechanical respiratory rate, $P a w_{\text {peak }}-C V$, coefficient of variation of airway inspiratory peak pressure, $E a d i_{p e a k}-C V$ coefficient of variation of diaphragmatic electrical activity peak

$* p<0.05$ vs. $\mathrm{PSV}_{1},{ }^{\dagger} p<0.05$ vs. NAVA detectable in PSV in absence of pathological modification of $\mathrm{FV}_{\text {mean }}$ ICP, cerebral haemodynamics and ABGs [46].

Our study has several limitations that deserve discussion. First, our results have been achieved across three 30-minlasting trials of ventilatory mode application. Although this observation time might seem quite short, it is in agreement with previous investigations evaluating not only NAVA application in invasive and non-invasive setting in course of acute respiratory failure [14, 17] but also the effects of arterial carbon dioxide tension modifications on cerebral blood flow velocity in anesthetized patients having surgery [47]. Second, the considered patients sample size was quite small. Nevertheless, it was in line with the sample sizes reported in several physiologic investigations conducted on NAVA application in different clinical settings [13, 14, 17, $18,41,48]$. Third, our study population was not homogeneous, mainly in regard to the type of acute brain injury. Further investigations about NAVA application in neurocritical care patients should therefore be planned by focusing on the specific aetiology of acute brain injury. Fourth, aiming to evaluate cerebral blood flow, we bilaterally performed TCCD sonography assessment only at MCA. While a full flow evaluation on three windows (temporal, orbital and foramen magnum) would be the optimal solution, MCA carries $50-60 \%$ of the ipsilateral carotid artery blood flow and thus can be considered to represent a great portion of the total blood flow to the hemisphere [21, 22], without losing the validity of our results. Fifth, it is worth to consider the technique limitations of TCCD sonography: (1) being an ultrasound evaluation, it is highly operator-dependent; (2) the measurements are limited to the large basal arteries and can only provide an index of global rather than local cerebral blood flow velocity [23]. To limit these variations, a unique operator conducted the cerebral blood flow sonographic evaluation. Lastly, in our setting a combination of propofol and remifentanil in continuous intravenous infusion was adopted as a sedation plan. Accordingly, the effects of these sedatives on neural respiratory drive [41, 42] must be taken into account in interpreting our data.

In conclusion, in our setting, NAVA was safely employed because, as well as PSV, it preserved the cerebral blood flow velocity, gas exchange and haemodynamics. In addition, as expected, NAVA improved PVI by enhancing patient-ventilator synchrony and assuring a more physiological breathby-breath $\mathrm{V}_{\mathrm{T}}$ variability, compared to PSV. Further studies are needed to investigate the clinical impact of NAVA in specific subsets of acutely-brain-injured patients.

Acknowledgements The authors wish to thank Dr Chiara Robba and Dr Anselmo Caricato for their supports in the study design.

Funding No additional funding has been employed to conduct the present investigation.

Data availability The data of the present trial will be available on specific request sent to gmcamma@gmail.com.

\section{Compliance with ethical standards}

Conflict of interest Dr. Messina reports personal fees and other from Vygon Italia, outside the submitted work. Dr. Navalesi reports personal fees from Getinge, outside the submitted work.

Ethical approval The present investigation was approved by Ethical Committee of Azienda Ospedaliero-Universitaria "Maggiore della Carità"- Novara, Italy (protocol No. CE 114/18).

\section{References}

1. Esteban A, Anzueto A, Frutos F, Alía I, Brochard L, Stewart TE, et al. Characteristics and outcomes in adult patients receiving 
mechanical ventilation: a 28-day international study. J Am Med Assoc. 2002;287:345-55.

2. Nyquist P, Stevens RD, Mirski MA. Neurologic injury and mechanical ventilation. Neurocrit Care. 2008;9:400-8.

3. Meng L, Hou W, Chui J, Han R, Gelb AW. Cardiac output and cerebral blood flow. Anesthesiology. 2015;123:1198-208.

4. Oddo M, Crippa IA, Mehta S, Menon D, Payen JF, Taccone FS, et al. Optimizing sedation in patients with acute brain injury. Crit Care. 2016;20:128.

5. Esteban A, Frutos-Vivar F, Muriel A, Ferguson ND, Peñuelas $\mathrm{O}$, Abraira V, et al. Evolution of mortality over time in patients receiving mechanical ventilation. Am J Respir Crit Care Med. 2013;188:220-30.

6. Thille AW, Rodriguez P, Cabello B, Lellouche F, Brochard L. Patient-ventilator asynchrony during assisted mechanical ventilation. Intensive Care Med. 2006;32:1515-22.

7. Giannouli E, Webster K, Roberts D, Younes M. Response of ventilator-dependent patients to different levels of pressure support and proportional assist. Am J Respir Crit Care Med. 1999; 159:1716-25.

8. De Wit M, Pedram S, Best AM, Epstein SK. Observational study of patient-ventilator asynchrony and relationship to sedation level. J Crit Care. 2009;24:74-80.

9. De Wit M, Miller KB, Green DA, Ostman HE, Gennings C, Epstein SK. Ineffective triggering predicts increased duration of mechanical ventilation. Crit Care Med. 2009;37:2740-5.

10. Bosma K, Ferreyra G, Ambrogio C, Pasero D, Mirabella L, Braghiroli A, et al. Patient-ventilator interaction and sleep in mechanically ventilated patients: Pressure support versus proportional assist ventilation. Crit Care Med. 2007;35:1048-54.

11. Blanch L, Villagra A, Sales B, Montanya J, Lucangelo U, Luján $\mathrm{M}$, et al. Asynchronies during mechanical ventilation are associated with mortality. Intensive Care Med. 2015;41:633-41.

12. Sinderby C, Navalesi P, Beck J, Skrobik Y, Comtois N, Friberg $\mathrm{S}$, et al. Neural control of mechanical ventilation in respiratory failure. Nat Med. 1999;5:1433-6.

13. Spahija J, De Marchie M, Albert M, Bellemare P, Delisle S, Beck J, et al. Patient-ventilator interaction during pressure support ventilation and neurally adjusted ventilatory assist. Crit Care Med. 2010;38:518-26.

14. Colombo D, Cammarota G, Bergamaschi V, De Lucia M, Della CF, Navalesi P. Physiologic response to varying levels of pressure support and neurally adjusted ventilatory assist in patients with acute respiratory failure. Intensive Care Med. 2008;34:2010-8.

15. Piquilloud L, Vignaux L, Bialais E, Roeseler J, Sottiaux T, Laterre $\mathrm{PF}$, et al. Neurally adjusted ventilatory assist improves patientventilator interaction. Intensive Care Med. 2011;37:263-71.

16. Yonis H, Crognier L, Conil JM, Serres I, Rouget A, Virtos M, et al. Patient-ventilator synchrony in neurally adjusted ventilatory assist (NAVA) and pressure support ventilation (PSV): A prospective observational study. BMC Anesthesiol. 2015;15:1-9.

17. Cammarota G, Olivieri C, Costa R, Vaschetto R, Colombo D, Turucz E, et al. Noninvasive ventilation through a helmet in postextubation hypoxemic patients: Physiologic comparison between neurally adjusted ventilatory assist and pressure support ventilation. Intensive Care Med. 2011;37:1943-50.

18. Cammarota G, Longhini F, Perucca R, Ronco C, Colombo D, Messina A, et al. New setting of neurally adjusted ventilatory assist during noninvasive ventilation through a helmet. Anesthesiology. 2016;125:1181-9.

19. Tobin MJ, Mador MJ, Guenther SM, Lodato RF, Sackner MA. Variability of resting respiratory drive and timing in healthy subjects. J Appl Physiol. 1988;65:309-17.

20. Vora YY, Suarez-Almazor M, Steinke DE, Martin ML, Findlay JM. Role of transcranial Doppler monitoring in the diagnosis of cerebral vasospasm after subarachnoid hemorrhage. Neurosurgery. 1999;44:1237-48.

21. Rutgers DR, Blankensteijn JD, Van Der Grond J. Preoperative MRA flow quantification in CEA patients: flow differences between patients who develop cerebral ischemia and patients who do not develop cerebral ischemia during cross-clamping of the carotid artery. Stroke. 2000;31:3021-8.

22. Moppett IK, Mahajan RP. Transcranial Doppler ultrasonography in anaesthesia and intensive care. Br J Anaesth. 2004;93:710-24.

23. Sushmita Purkayastha PhD, Farzaneh MDP. Transcranial Doppler ultrasound: technique and application. Semin Neurol. 2014;32:411-20.

24. Lindegaard KF, Nornes H, Bakke SJ, Sorteberg W, Nakstad P. Cerebral vasospasm after subarachnoid haemorrhage investigated by means of transcranial Doppler ultrasound. Acta Neurochir Suppl (Wien). 1988;42:81-4.

25. Lamouret O, Crognier L, Bounes FV, Conil JM, Dilasser C, Raimondi T, et al. Neurally adjusted ventilatory assist (NAVA) versus pressure support ventilation: patient-ventilator interaction during invasive ventilation delivered by tracheostomy. Crit Care. 2019;23:1-9.

26. Bouzat P, Sala N, Payen JF, Oddo M. Beyond intracranial pressure: Optimization of cerebral blood flow, oxygen, and substrate delivery after traumatic brain injury. Ann Intensive Care. 2013;3:1-9.

27. Clifton GL, Miller ER, Choi SC, Levin HS. Fluid thresholds and outcome from severe brain injury. Crit Care Med. 2002;30:739-45.

28. Frost EAM. Effects of positive end expiratory pressure on intracranial pressure and compliance in brain injured patients. J Neurosurg. 1977;47:195-200.

29. Coles JP, Fryer TD, Coleman MR, Smielewski P, Gupta AK, Minhas PS, et al. Hyperventilation following head injury: effect on ischemic burden and cerebral oxidative metabolism. Crit Care Med. 2007;35:568-78.

30. Coles JP, Minhas PS, Fryer TD, Smielewski P, Aigbirihio F, Donovan T, et al. Effect of hyperventilation on cerebral blood flow in traumatic head injury: clinical relevance and monitoring correlates. Crit Care Med. 2002;30:1950-9.

31. Oddo M, Nduom E, Frangos S, MacKenzie L, Chen I, MaloneyWilensky E, et al. Acute lung injury is an independent risk factor for brain hypoxia after severe traumatic brain injury. Neurosurgery. 2010;67:338-44.

32. Asehnoune K, Roquilly A, Cinotti R. Respiratory management in patients with severe brain injury. Crit Care. 2018;22:1-6.

33. Boone MD, Jinadasa SP, Mueller A, Sheafi S, Kasper EM, Hanafy $\mathrm{KA}$, et al. The effect of positive end-expiratory pressure on intracranial pressure and cerebral hemodynamics. Neurocrit Care. 2017;26:174-81.

34. McCredie VA, Ferguson ND, Pinto RL, Adhikari NKJ, Fowler RA, Chapman MG, et al. Airway management strategies for braininjured patients meeting standard criteria to consider extubation: a prospective cohort study. Ann Am Thorac Soc. 2017;14:85-93.

35. De Riva N, Budohoski KP, Smielewski P, Kasprowicz M, Zweifel C, Steiner LA, et al. Transcranial doppler pulsatility index: what it is and what it isn't. Neurocrit Care. 2012;17:58-66.

36. Mascia L, Zavala E, Bosma K, Pasero D, Decaroli D, Andrews $\mathrm{P}$, et al. High tidal volume is associated with the development of acute lung injury after severe brain injury: an international observational study. Crit Care Med. 2007;35:1815-20.

37. Longhini F, Pan C, Xie J, Cammarota G, Bruni A, Garofalo E, et al. New setting of neurally adjusted ventilatory assist for noninvasive ventilation by facial mask: a physiologic study. Crit Care. 2017;21:170.

38. Longhini F, Liu L, Pan C, Xie J, Cammarota G, Bruni A, et al. Neurally-adjusted ventilatory assist for noninvasive ventilation via 
a helmet in subjects with copd exacerbation: a physiologic study. Respir Care. 2019;64:582-9.

39. Ferreira JC, Diniz-Silva F, Moriya HT, Alencar AM, Amato MBP, Carvalho CRR. Neurally adjusted ventilatory assist (NAVA) or pressure support ventilation (PSV) during spontaneous breathing trials in critically ill patients: a crossover trial. BMC Pulm Med. 2017; 17:1-9.

40. Froman C. Alterations of respiratory function in patients with severe head injuries. Br J Anaesth. 1968;40:354-60.

41. Vaschetto R, Cammarota G, Colombo D, Longhini F, Grossi F, Giovanniello A, et al. Effects of propofol on patient-ventilator synchrony and interaction during pressure support ventilation and neurally adjusted ventilatory assist. Crit Care Med. 2014;42:74-82.

42. Costa R, Navalesi P, Cammarota G, Longhini F, Spinazzola G, Cipriani F, et al. Remifentanil effects on respiratory drive and timing during pressure support ventilation and neurally adjusted ventilatory assist. Respir Physiol Neurobiol. 2017;244:10-6.

43. Barr J, Fraser GL, Puntillo K, Ely EW, Gélinas C, Dasta JF, et al. Clinical practice guidelines for the management of pain, agitation, and delirium in adult patients in the intensive care unit: executive summary. Am J Heal Pharm. 2013;70:53-8.
44. Jackson DL, Proudfoot CW, Cann KF, Walsh T. A systematic review of the impact of sedation practice in the ICU on resource use, costs and patient safety. Crit Care. 2010;14:R59.

45. Berger KI, Sorkin IB, Norman RG, Rapoport DM, Goldring RM. Mechanism of relief of tachypnea during pressure support ventilation. Chest. Am Coll Chest Physicians. 1996;109:1320-7.

46. Cammarota G, Sguazzotti I, Della Corte F, Cheyne VR. Stokes breathing pattern and neurally adjusted ventilatory assist in a neuro - critical patient. Intensive Care Med. 2020;46:540-1.

47. Grüne F, Kazmaier S, Stolker RJ, Visser GH, Weyland A. Carbon dioxide induced changes in cerebral blood flow and flow velocity: role of cerebrovascular resistance and effective cerebral perfusion pressure. J Cereb Blood Flow Metab. 2015;35:1470-7.

48. Longhini F, Ferrero F, De Luca D, Cosi G, Alemani M, Colombo $\mathrm{D}$, et al. Neurally adjusted ventilatory assist in preterm neonates with acute respiratory failure. Neonatology. 2015;107:60-7.

Publisher's Note Springer Nature remains neutral with regard to jurisdictional claims in published maps and institutional affiliations. 